\title{
MAKER: Smart Packaging Machine Simulator for Teaching Ladder Logic Programming
}

\section{Mr. Robert Barham, New Caney ISD}

Robert Barham has been teaching secondary math and technology courses for twenty years. Currently, he teaches engineering courses at Porter High School in Porter, Texas, some forty miles northeast of Houston. He is working with the local community college to articulate acceptance of high school robotics and automation courses toward the requirements of an A.A.S. degree in mechatronics. Email: rbarham@ newcaneyisd.org

\section{Dr. Sheng-Jen "Tony" Hsieh, Texas A\&M University}

Dr. Sheng-Jen ("Tony") Hsieh is a Professor in the Dwight Look College of Engineering at Texas A\&M University. He holds a joint appointment with the Department of Engineering Technology and the Department of Mechanical Engineering. His research interests include engineering education, cognitive task analysis, automation, robotics and control, intelligent manufacturing system design, and micro/nano manufacturing. He is also the Director of the Rockwell Automation laboratory at Texas A\&M University, a state-of-the-art facility for education and research in the areas of automation, control, and automated system integration. 


\title{
MAKER: Smart Packaging Machine Simulator for Teaching Ladder Logic Programming
}

\begin{abstract}
This paper describes the results of an instructional pilot in programmable logic controller (PLC) programming in the ladder-logic language. As an extra-credit opportunity, students were invited to participate in a programming activity in ladder-logic that consisted of the following: 1) a preinstructional assessment of prior knowledge, (2) an online slideshow presentation that introduces PLCs, including future training and employment opportunities, (3) an online post-instructional assessment of acquired knowledge, and (4) an opinion survey designed to measure student demand for a course that teaches industrial automation. These data were meant to be shared with school administration so that changes to the course catalog would be properly informed by documented student need. The instructional machine was created as a result of attending a Summer Research Experiences for Teachers program at Texas A\&M University in 2016.
\end{abstract}

\section{Motivation}

The state of Texas in the 2015 legislative session adopted changes to the state curriculum document, the Texas Essential Knowledge and Skills. Among the changes scheduled for the fall of 2017 is the elimination of the course Robotics and Automation [1] (See subchapter O, downloaded January 10, 2017). This course will be replaced by two, Robotics I (TEKS $\S 130.408$.) and Robotics II (TEKS §130.409.)[1]. Robotics II is an entirely new course, whereas Robotics I subsumes the student expectations and learning outcomes of Robotics and Automation. This new Robotics II course represents an opportunity to leverage some of the technical advances in microcircuitry to bring industrial automation instruction to the public school classroom. The benefits of this are many.

When compared to other computing professionals, PLC technicians earn high salaries. Furthermore, their training requires only two-year college instruction. According to the national salary survey results at Automation.com [2], respondents with only a high school diploma as the highest attained degree averaged a salary of $\$ 94,239$. This represents a large return on educational investment when compared to professional training of four-year universities. The reason is, as the Texas Higher Education Coordinating Board (THECB) has observed, "The demand for skilled and knowledgeable workers continues to outpace workforce supply in Texas," [3]. THECB has a long term strategy to meet bot the needs of employers for technically skilled employees and the economic needs of young Texans for reliable employment. The document " $60 \times 30$ TX" explicitly states the goal of holding the level of undergraduate debt to " 60 percent of first-year wages after college" [4]. Community college systems in Texas are therefore encouraged to partner with local K-12 educational agencies to articulate credit for engineering courses offered in high school. Many of these two-year degrees articulate seamlessly into four-year engineering technology degrees, the requirements of which are met entirely at the local two-year campus. Thus, the financial burden to families of providing their children with a professional education is dramatically reduced, as is the time required to educate the student to a level sufficient to earn a significant income. This project was a step toward creating a high school course in industrial automation that would meet at least one of the requirements for a local community college's degree in process technology or mechatronics. 
Indeed, an important part of this instructional module is information about continued training locally available.

With advances in microcircuitry, an entire class set of twenty PLCs can be stored stored in a shoebox and purchased for less than \$5000 [5]. Both of these are important criteria for a public school. Storage space is at a premium in most classrooms and budgets for instructional materials are stretched to their limits. The currently deployed controllers made by VEX and Fischertechnik are far more expensive and bulky. Table 1 shows the costs, dimensions, and capabilities of various controlling units available for instruction.

\begin{tabular}{|c|c|c|c|c|c|c|c|}
\hline Controller & Language & Analog Inputs & Digital Inputs & Digital Outpus & Cost & $\begin{array}{l}\text { Dimensions (in) wihout } \\
\text { power supply }\end{array}$ & Volume (cub in) \\
\hline VEX Robotics & C & 12 & 8 & 10 & $\$ 250.00$ & $4.5 \times 3.9 \times 1$ & 17.55 \\
\hline Fischertechnik & C & 0 & 4 & 4 & $\$ 345.00$ & $3.5 \times 3.5 \times 1$ & 12.25 \\
\hline Arduino R3 & $\mathrm{C}$ & 0 & 14 (In or out, the & user decides) & $\$ 22.00$ & $3.1 \times 2.2 \times 1$ & 6.82 \\
\hline Raspberry Pi & $\mathrm{C}$ & 0 & 17 (In or out, the & user decides) & $\$ 50.00$ & $3.3 \times 2.2 \times 1$ & 7.26 \\
\hline Velocio Ace & Ladder Lg & 12 & 12 & 12 & $\$ 149.00$ & $2.5 \times 2.5 \times 1$ & 6.25 \\
\hline
\end{tabular}

Table 1. Comparison of Controller Units

A VEX Coretex microcontroller currently costs $\$ 249$ (downloaded January 10, 2017) and has dimensions of 4.5" W x 3.9" L x 1" H (17.55 cu-in) [6]. The Fischertechnik controller costs $\$ 345$ (, downloaded January 10, 2017) and has dimensions of 3.5 x 3.5 x 1 inches (12.25 cu-in) [7]. An Ace controller with twelve digital inputs, twelve analog inputs, and twelve digital outputs costs $\$ 149$ ( downloaded January 10, 2017) and has dimensions of 2.5" x 2.5" x 0.5 " (3.125 cu in) [8]. Other choices of controller are Raspberry Pi kits (\$50) [9] and Arduino (\$22 if purchased with a power supply) [10]. These are good choices for teaching mechatronic programming in the $\mathrm{C}$ language, and their use is the subject of subsequent research.

As an introduction to a documented engineering problem, students were shown a machine which simulates the automatic packaging of small foods. There is some literature about methods to ensure hygienic food handling in smart packaging systems [11]. The problems addressed have to do mostly with controlling salmonella or listeria microbes [12], and the solutions proposed range from nanotechnology to recommending stainless steel construction [13]. What we can take away from this is that there is a documented need to make packaging systems smart- certain conditions inherent in the packaging process threaten the quality of the product. Sensors detect these conditions, communicate them to a controller, and the controller does something to make the machine more hygienic.

\section{Instructional Machine}

This packaging machine (see Figure 1) has a sensor to detect the proximity of foam cup vessels on a motorized conveyor, and another proximity sensor to detect the level of product in the cup. There is a hopper containing product, and a servo motor controls a gate which releases the small food items into a chute made of VEX c-channel inclined gradually to control the speed of the delivery. A Fischertechnik thermal switch controls a fan motor, and an incandescent lamp warms that switch. The fan and thermal switch represent an HVAC system that senses operating temperature and cools the product automatically when a certain temperature is reached. When 
the fan comes on, the lamp turns off, allowing the thermal switch to cool. When cool, the thermal switch opens, turning off the fan, and the PLC turns the lamp back on.

Table 2 lists the parts and costs of the machine.

\begin{tabular}{|c|c|c|c|}
\hline Part or component & Unit Cost & & Subtotal \\
\hline 12 VDC/360 W power supply & $\$ 15.99$ & 1 & $\$ 15.99$ \\
\hline step-down transformer to $5 \mathrm{~V}$ & $\$ 10.95$ & 1 & $\$ 10.95$ \\
\hline Velocio Ace 222v10 PLC & $\$ 149.00$ & 1 & $\$ 149.00$ \\
\hline 2 capacitive proximity sensors, & $\$ 8.78$ & 2 & $\$ 17.56$ \\
\hline Fischertechnik heat sensor & Legacy & NA & \\
\hline Fischertechnik lamp & Legacy & NA & \\
\hline 2-wire VEX motor & $\$ 14.99$ & 1 & $\$ 14.99$ \\
\hline 3-wire VEX servo & $\$ 19.99$ & 1 & $\$ 19.99$ \\
\hline Motorized pinwheel & $\$ 2.50$ & 1 & $\$ 2.50$ \\
\hline 1 Gallon plastic jug & $\$ 2.57$ & 1 & $\$ 2.57$ \\
\hline Foam cups (package of 20) & $\$ 0.77$ & 1 & $\$ 0.77$ \\
\hline VEX conveyors, sprockets, axles, bearings, connectors, and structural pieces & Legacy & NA & \\
\hline Electronics breadboard & $\$ 51.50$ & 1 & $\$ 51.50$ \\
\hline Flexible straws (conduit), craft sticks, and custom parts fabricated from plywood. & Legacy & NA & \\
\hline & Grand Total & & 285.82 \\
\hline
\end{tabular}

Table 2. Packaging Machine Components and Costs

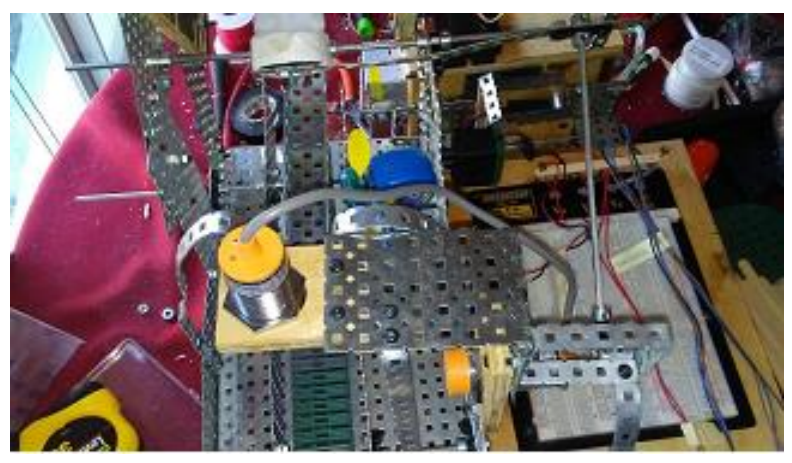

Figure 1. Packaging Machine

\begin{tabular}{|l|l|l|l|}
\hline Input Address & Device (In) & Output Address & Device (Out) \\
\hline B1 & Thermal Switch & D1 & Lamp \\
\hline B2 & On Switch & D2 & Conveyor Motor \\
\hline B3 & Horinzontal Proximity Sensor & D3 & Hopper Servo \\
\hline B4 & Vertical Proximity Sensor & D4 & Fan Motor \\
\hline
\end{tabular}

Table 3 Input and Output Address Allocations 


\section{Ladder Logic}

The programmatic logic of this machine is simple. Four outputs require a total of six rungs, with Rungs 4-6 controlling the servo. Table 4 lists the input conditions and output states that the PLC creates in the program.

\begin{tabular}{|c|c|c|}
\hline Rung No. & $\begin{array}{c}\text { Input Condition } \\
\text { (assume "check closed" unless } \\
\text { otherwise) }\end{array}$ & $\begin{array}{c}\text { Output State } \\
\text { ("energize" unless otherwise) }\end{array}$ \\
\hline 1 & $\begin{array}{l}\text { On Switch AND (open Thermal Switch } \\
\text { OR open Fan) }\end{array}$ & Lamp \\
\hline 2 & Thermal Sw AND (open Lamp) & Fan \\
\hline 3 & $\begin{array}{l}\text { (Horiz Sensor AND Vert Sensor) OR } \\
\text { (open Horiz Sensor AND open Vert } \\
\text { Sensor) }\end{array}$ & Conveyor \\
\hline 4 & Conveyor open & PWM: Set period 20000 micr.sec. \\
\hline 5 & open Vert Sensor & $\begin{array}{l}\text { PWM: start servo, } 19000 \text { micr. } \\
\text { sec. signal (reverse) }\end{array}$ \\
\hline 6 & Vert Sensor & $\begin{array}{l}\text { PWM: start servo, } 18500 \text { micr. } \\
\text { sec. signal (neutral) }\end{array}$ \\
\hline
\end{tabular}

Table 4. Rung Instructions in Ladder Logic

Rung 1 controls the lamp which is used to heat the thermal switch to simulate hot working conditions and activate the cooling fan. The on switch toggles to energize the machine, and as long as the thermal switch is open and the fan is not running, the lamp energizes. This is an incandescent lamp, not an LED.

Rung 2 defines the conditions for turning on the fan. When the ambient temperature is sufficient to close the thermal switch, the lamp turns off and the fan motor energizes.

Rung 3 controls the conveyor motor. There are two conditions which will energize the conveyor. The first is the situation in which no vessel is close enough to activate the proximity sensors. In this case, both sensors are "open," and the conveyor energizes. The second situation in the one in which a vessel has been filled with product and should be ejected from the system. In this case, both proximity sensors close and energize the conveyor to eject the full vessel and position a new empty.

Rung 4 is a PWM output that sets the servo period at an industry standard of 20000 microseconds. When the conveyor stops, the period is set using a PWM output.

Rung 5 uses a PWM pulse to reverse the VEX servo and thus open the hopper gate. When the vertical sensor is open, the hopper releases product in an empty vessel waiting below a loading chute. Since the output transistors on the ACE PLC are of the NPN variety ("sinking"), the usual $1 \mathrm{~ms}$ pulse must be modified by subtracting from the $20 \mathrm{~ms}$ period. Values are converted to microseconds for VBuilder. 
Rung 6 uses a PWM pulse to reset the VEX servo to its neutral position, thus closing the hopper gage. When the vertical sensor closes, it means the vessel beneath it is full. The signal to reset a VEX servo to neutral is $1.5 \mathrm{~ms}$, which converts to 18500 microseconds for the ACE.

On the ACE, there are six banks of ports labeled A through F. Each bank (of the ACE 222) has eight connections, two of which are for ground and voltage, leaving six ports free for device connections. Figure 8 is a capture from the online user's manual on the velocio.net website. It shows the port locations and types for this PLC [14].

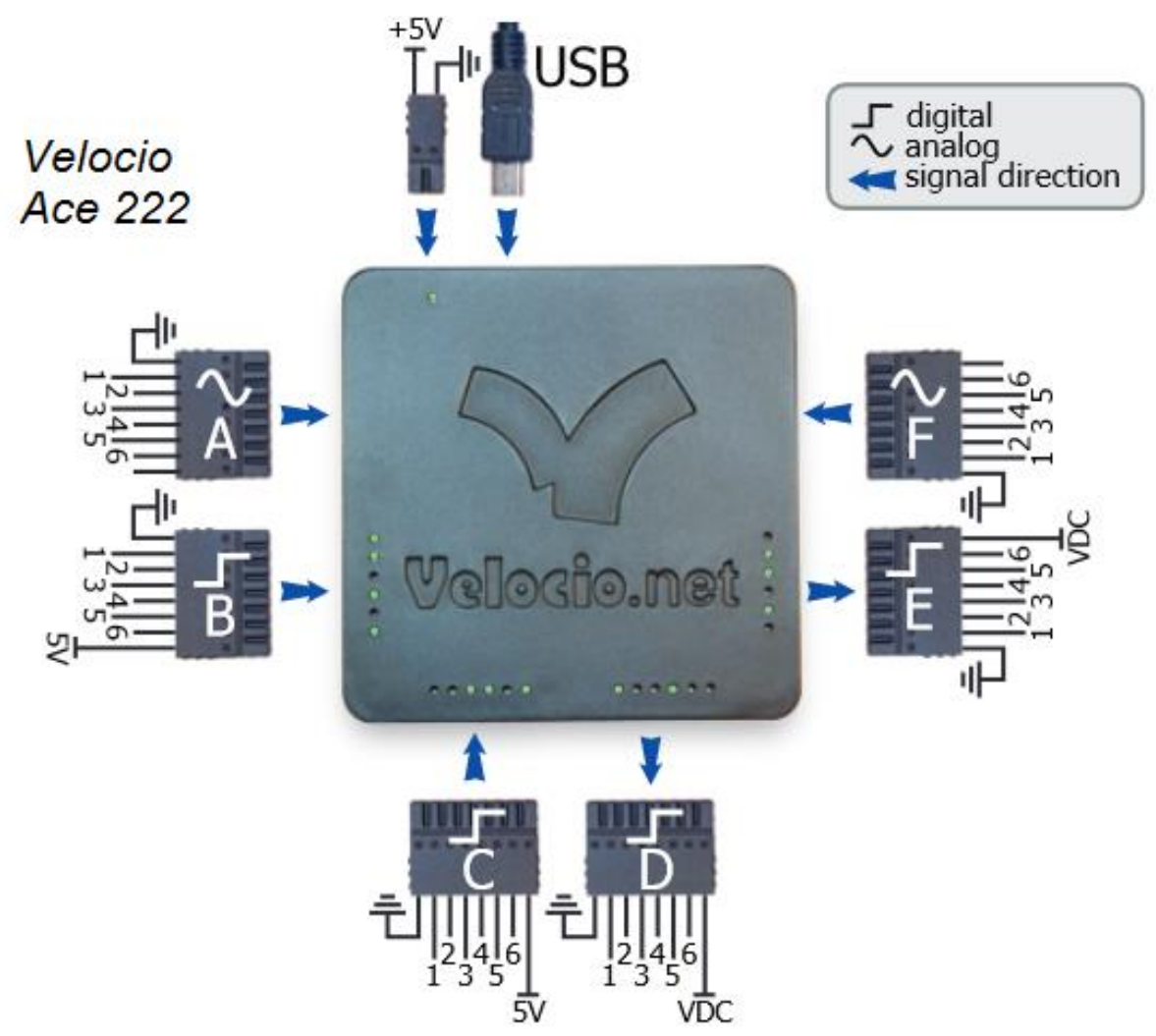

Figure 8. Velocio Ace PLC 222v10

\section{Presentation and assessment}

Students were given an assessment of prior knowledge before being shown the presentation which introduced the properties of PLCs and explained their importance in industry. The presentation compared PLCs to other computing devices with which they are familiar, like microcontrollers and PCs. It also provided employment opportunity data, and instructions for obtaining further training locally. The post-instruction assessment used the same question items as the pre-instruction assessment, but the items were presented in a different order. Students were offered five points of extra credit as incentive for participating. The purpose of the two assessments was to identify areas of confusion caused by the slideshow with a view toward future changes. A comparison of the pre and post instructional assessment data provided insight 
into the accessibility of a mechatronics curriculum for high school students. Currently, this is a course offered in college, so there was some concern that high school students might find the subject matter too rigorous.

\section{Opinion survey}

As this is a data-gathering activity, it recorded the students' opinions rather than evaluated their performance. Using Google Forms, students were asked to rate their interest on a five point likert scale with five showing great interest, one meaning no interest, and three being neutral. Table 5 shows the survey items:

\begin{tabular}{|c|c|}
\hline \multicolumn{2}{|c|}{ Survey Items } \\
\hline Item 1 & I would like to learn more about sensors. \\
\hline Item 2 & I would like to learn more about motor control. \\
\hline Item 3 & $\begin{array}{l}\text { I would like to learn how to program a variety of microcontrollers (Arduino, } \\
\text { Raspberry } \mathrm{Pi} \text { ). }\end{array}$ \\
\hline Item 4 & With more training, I feel like I could program a machine in Ladder Logic. \\
\hline Item 5 & $\begin{array}{l}\text { I would like to learn more about college training for process technology, automation, } \\
\text { or mechatronics. }\end{array}$ \\
\hline Item 6 & I would like to learn more about PLCs \\
\hline
\end{tabular}

Table 5 Survey Items: Students Rating Interest on a 1-5 Scale

Since this project was designed to document student interest in automation courses, students were asked to respond to rate their own interest in further instruction on a 1-5 Likert scale.

\section{Results}

Nine students took both the pre and post-instructional assessments. Their results are presented in Table 6. The one-tailed, paired T-test was calculated manually and the significance was determined from a t-table [15] available online. The mean pre-assessment score was 58 and the mean post-assessment score was 83 . This mean difference produced a t-test of 3.18 which is a significant result even at the .01 level. The null hypothesis that mechatronic instruction is not effective for high school students was therefore rejected. 


\begin{tabular}{|l|l|l|}
\hline Participant & Pre- score & Post- score \\
\hline 1 & 72 & 90 \\
\hline 2 & 81 & 81 \\
\hline 3 & 63 & 90 \\
\hline 4 & 63 & 90 \\
\hline 5 & 54 & 99 \\
\hline 6 & 63 & 81 \\
\hline 7 & 72 & 90 \\
\hline 8 & 18 & 45 \\
\hline 9 & 36 & 81 \\
\hline Means & 58 & 83 \\
\hline st. devs & 18.54723699 & 14.56021978 \\
\hline Counts & 9 & 9 \\
\hline Variances & 344 & 212 \\
\hline T-Test & 3.180708486 & $\mathrm{p}<.05^{*}$ \\
\hline
\end{tabular}

Table 6. Results of the Pre- and Post Assessments

The results of the opinion survey are shown in Table 7.

\begin{tabular}{|l|l|l|l|l|l|}
\hline Item 1 & Item 2 & Item 3 & Item 4 & Item 5 & Item 6 \\
\hline 5 & 5 & 5 & 5 & 5 & 5 \\
\hline 4 & 4 & 5 & 5 & 3 & 4 \\
\hline 4 & 4 & 4 & 4 & 4 & 4 \\
\hline 3 & 3 & 2 & 3 & 3 & 3 \\
\hline 3 & 4 & 5 & 4 & 4 & 4 \\
\hline Item 1 Mean & Item 2 Mean & Item 3 Mean & Item 4 Mean & Item 5 Mean & Item 6 Mean \\
\hline 3.8 & 4 & 4.2 & 4.2 & 3.8 & 4 \\
\hline
\end{tabular}

Table 7 Results of Opinion Survey

The mean for all six items was 4 . Compared to a neutral 3, this represents a t-test (one-tailed, paired) of 13.69, a significant result ( $\mathrm{p}<.05)$. The null hypothesis that there was no interest in a mechatronics class at the high school level was also rejected. There were only five participants in the survey, and this was a disappointing response rate. However, at the school where the survey was administered, four are the required minimum to make a course. The results are therefore valuable. 


\section{Acknowledgements}

This material is based upon work supported by the Research Experiences for Teachers Program under National Science Foundation Grant No. 1300779. Any opinions, findings, and conclusions or recommendations expressed in this material are those of the author(s) and do not necessarily reflect the views of National Science Foundation.

\section{References}

[1] Online resource available at http://tea.texas.gov/WorkArea/DownloadAsset.aspx?id=51539607555

[2] Online resource available at http://www.automation.com/salary-survey-results-2015/past-salary-survey-results/salary-surveyresults-2015

[3] Texas Higher Education Coordinating Board, (2015), 60 x 30 TX, http://www.thecb.state.tx.us/reports/PDF/6862.PDF?CFID=41531877\&CFTOKEN=29618147

[4] Texas Higher Education Coordinating Board, (2015), 60 x 30 TX, p. 26, http://www.thecb.state.tx.us/reports/PDF/6862.PDF?CFID=41531877\&CFTOKEN=29618147

[5] Online resource available at http://velocio.net/ace/

[6] Online resource available at http://www.vexrobotics.com/276-2194.html

[7] Online resource available at https://www.amazon.com/fischertechnik-522429-FischertechnikRobotics-Controller/dp/B00J8G9IQ4/ref=sr_1_1?s=toys-and-

games\&ie=UTF8\&qid=1484060686\&sr=1-1\&keywords=fischertechnik + controller

[8] Online resource available at http://velocio.net/ace/

[9] Online resource available at https://www.amazon.com/dp/B01D92SSX6/ref=psdc_3015426011_t2_B01C6Q2GSY

[10] Online resource available at https://www.amazon.com/Arduino-Uno-R3-Microcontroller-

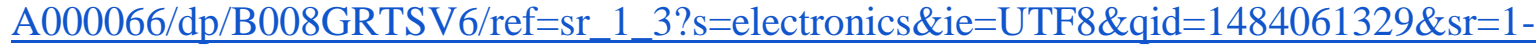
$\underline{3 \& \text { keywords=arduino }}$

[11] Kaarina Aarnisalo, Kaija Tallavaara, Gun Wirtanen, Riitta Maijala, Laura Raaska, “The Hygienic Working Practices of Maintenance Personnel and Equipment Hygiene in the Finnish Food Industry," Food Control 17. January, 2006.

[12] Aguado, V., Vitas, A. I., García-Jalón, I., "Random Amplified Polymorphic DNA Typing Applied to the Study of Cross-Contamination by Listeria monocytogenes in Processed Food Products," Journal of Food Protection, Number 5. May, 2001. pp. 599-743, pp. 716-720. [13] Mahalik, Nitaigour P., "Processing and packaging automation systems: a review," Sens. \& Instrumen. Food Qual., February, 2009.

[14] Online resource available at http://velocio.net/wp-content/uploads/2014/03/AceDS.pdf [15] Online resource available at http://www.sjsu.edu/faculty/gerstman/StatPrimer/t-table.pdf 